\title{
A Proposed Mechanism for the Asymmetric Duration of El Niño and La Niña
}

\author{
YUKO M. OKUMURA \\ Climate and Global Dynamics Division, National Center for Atmospheric Research, * Boulder, Colorado \\ MASAMICHI OHBA \\ Central Research Institute of Electric Power Industry, Abiko, Japan \\ Clara Deser \\ Climate and Global Dynamics Division, National Center for Atmospheric Research, * Boulder, Colorado \\ HIROAKI UEDA \\ Graduate School of Life and Environmental Sciences, University of Tsukuba, Tsukuba, Japan
}

(Manuscript received 13 August 2010, in final form 13 May 2011)

\begin{abstract}
El Niño and La Niña exhibit significant asymmetry not only in their spatial structure but also in their duration. Most El Niños terminate rapidly after maturing near the end of the calendar year, whereas many La Niñas persist into the following year and often reintensify in boreal winter. Through atmospheric general circulation model experiments, it is shown that the nonlinear response of atmospheric deep convection to the polarity of equatorial Pacific sea surface temperature anomalies causes an asymmetric evolution of surface wind anomalies over the far western Pacific around the mature phase of El Niño and La Niña. Because of the eastward displacement of precipitation anomalies in the equatorial Pacific during El Niño compared to La Niña, surface winds in the western Pacific are more affected by SST forcing outside the equatorial Pacific, which acts to terminate the Pacific event.
\end{abstract}

\section{Introduction}

Dynamic and thermodynamic feedbacks between the atmosphere and ocean give rise to the El Niño-Southern Oscillation (ENSO) phenomenon in the equatorial $\mathrm{Pa}-$ cific, the dominant mode of climate variability on interannual time scales. While the tremendous advance in our understanding of ENSO builds upon a linear view of the ocean-atmosphere system, studies over the past few decades reveal that warm (El Niño) and cold (La Niña) ENSO events are not a simple mirror image. For example,

\footnotetext{
* The National Center for Atmospheric Research is sponsored by the National Science Foundation.
}

Corresponding author address: Dr. Yuko M. Okumura, Climate and Global Dynamics Division, NCAR, P.O. Box 3000, Boulder, CO 80307.

E-mail: yukoo@ucar.edu sea surface temperature (SST) anomalies over the eastern equatorial Pacific cold tongue are larger in magnitude during El Niño compared to La Niña, resulting in positive skewness of interannual SST variations (e.g., Burgers and Stephenson 1999). In addition, equatorial Pacific precipitation anomalies are displaced eastward during El Niño compared to La Niña. Nonlinear processes in the atmosphere are fundamental for this asymmetry: large positive SST anomalies can induce deep convection over the cold tongue, while negative anomalies have no further effect on the normally dry conditions (Hoerling et al. 1997). The accompanying zonal shift in surface wind anomalies, in turn, is suggested to cause the stronger SST anomalies in the eastern Pacific during El Niño compared to La Niña (Kang and Kug 2002). Jin et al. (2003) propose that nonlinear thermal advection by ocean currents contributes to the generation of larger-amplitude El Niños compared to La Niñas. McPhaden and Zhang (2009) also note the asymmetry in 
the zonal propagation characteristics of El Niño and La Niña.

In addition to the spatial structure, recent studies also point out the asymmetry in the duration of El Niño and La Niña (Kessler 2002; Larkin and Harrison 2002; McPhaden and Zhang 2009; Ohba and Ueda 2009; Wu et al. 2010; Okumura and Deser 2010; Ohba et al. 2010). Figure 1 shows the composite evolution of SST, surface wind, and precipitation anomalies along the equator for El Niño and La Niña based on observations during 1982-2008. In the composite El Niño, positive SST anomalies decay rapidly after the mature phase in December and are replaced by negative values in JuneJuly of the following year. Conversely, in the composite La Niña, negative SST anomalies persist throughout the following year and reintensify in boreal winter. The prolongation of La Niña conditions into the second year is associated with persistent easterly wind anomalies over the western Pacific. In contrast, the anomalous westerly winds during El Niño begin to weaken over the far western Pacific 1-2 months before the mature phase. Compared to El Niño, the larger-amplitude zonal wind anomalies over the western Pacific during La Niña are associated with a westward displacement of the anomalous precipitation. Okumura and Deser (2010) show that this asymmetry in the duration of El Niño and La Niña is a robust feature of ENSO throughout the past century.

Ohba and Ueda (2009) show that an atmospheric general circulation model (AGCM) reproduces the asymmetric evolution of surface wind anomalies around the mature phase when forced with Indo-Pacific SST anomalies that are symmetrical between El Niño and La Niña. Their result suggests the importance of nonlinear atmospheric processes for the asymmetric evolution of El Niño and La Niña. It remains unclear what is the relative importance of SST forcing in the different parts of the Indo-Pacific region for the asymmetric wind evolution.

Based on observational analysis, Okumura and Deser (2010) synthesized previous findings and proposed a more detailed mechanism for the asymmetric wind response, as summarized in Fig. 2. During El Niño, delayed basin warming of the Indian Ocean increases tropospheric temperatures and forces a baroclinic atmospheric Kelvin wave into the western Pacific, inducing anomalous surface easterly winds in the western equatorial Pacific. The associated Ekman divergence suppresses atmospheric deep convection in the northwest tropical Pacific, forcing an anomalous anticyclonic circulation and enhancing the anomalous easterly winds north of the equator (Watanabe and Jin 2002; Annamalai et al. 2005; Xie et al. 2009). The negative SST
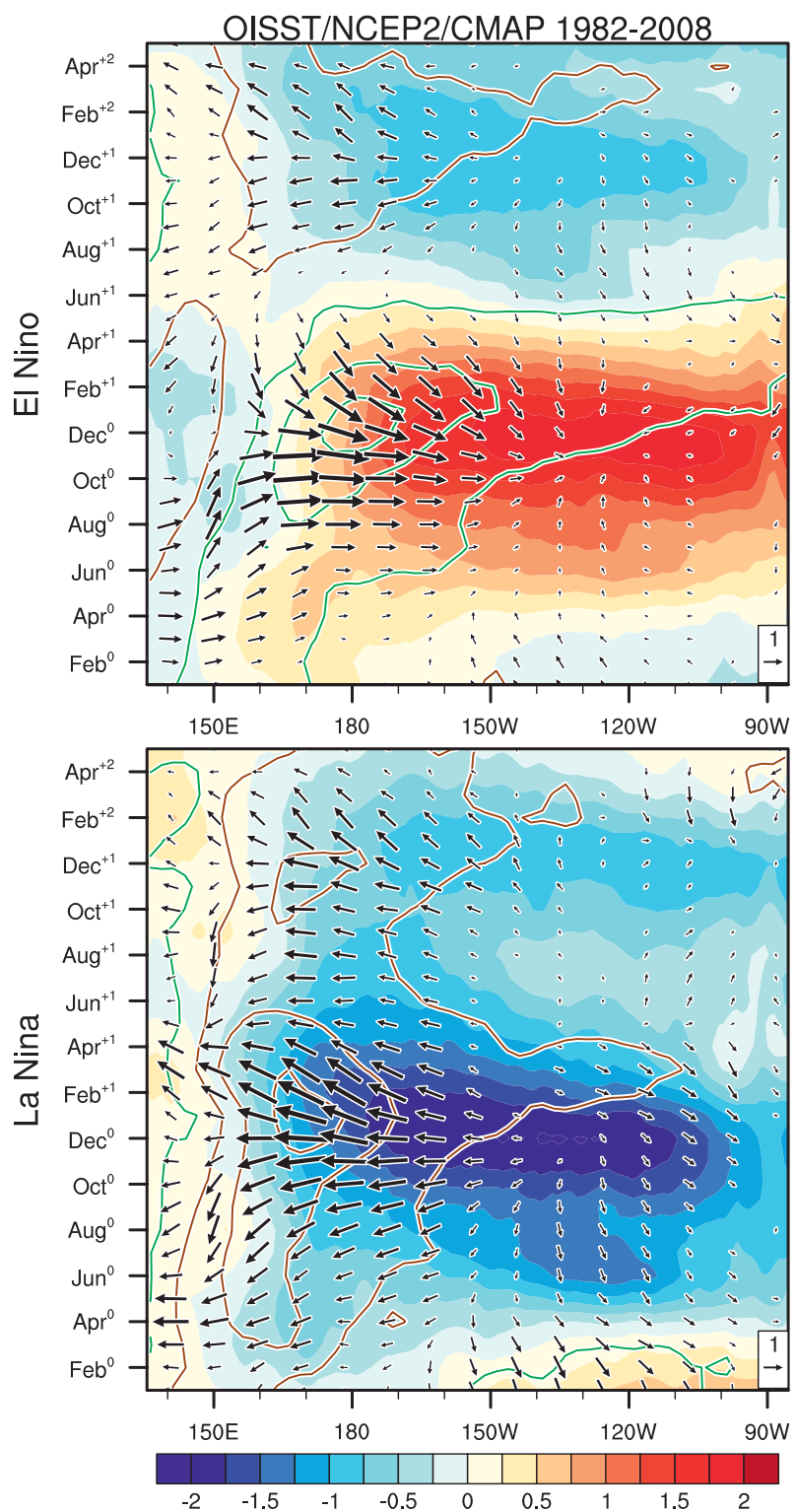

FIG. 1. Longitude-time sections of SST $\left({ }^{\circ} \mathrm{C}\right.$, color shading), surface wind ( $\mathrm{m} \mathrm{s}^{-1}$, vectors), and precipitation $\left[\mathrm{mm} \mathrm{day}^{-1}\right.$; positive (negative) contours in green (orange) at $\pm 1,3,5, \ldots]$ anomalies along the equator $\left(3^{\circ} \mathrm{S}-3^{\circ} \mathrm{N}\right)$ for (top) El Niño and (bottom) La Niña based on the Optimum Interpolation Sea Surface Temperature (OISST) (Reynolds et al. 2002), National Centers for Environmental Prediction-Department of Energy (NCEP-DOE) Reanalysis II (Kanamitsu et al. 2002), and Climate Prediction Center Merged Analysis of Precipitation (CMAP) (Xie and Arkin 1996) data for 1982-2008. The anomalies are composited for strong El Niño (1982, 1986, 1987, 1991, 1994, 1997, 2002, and 2006) and La Niña (1984, 1988, 1998, 1999, and 2007) years defined as in Okumura and Deser (2010). The time axis runs from January of the El Niño/La Niña year $\left(\operatorname{Jan}^{0}\right)$ to May of the year after the following year $\left(\mathrm{May}^{+2}\right)$. 
anomalies and local air-sea interactions within the northwest tropical Pacific may also contribute to the formation and maintenance of the anomalous anticyclonic circulation (Wang et al. 2000; Lau and Nath 2003). In the far western equatorial Pacific, the anomalous surface easterly wind forced by the Indian Ocean warming offsets or even reverses the anomalous westerly wind forced by the positive precipitation anomalies in the equatorial Pacific and rapidly terminates the event after the mature phase (e.g., Kug and Kang 2006; Ohba and Ueda 2007). During La Niña, however, the anomalous easterly wind forced by the negative precipitation anomalies in the equatorial Pacific is much stronger than the surface westerly wind induced by the Indian Ocean cooling because of the westward shift of the Pacific precipitation anomalies. The net easterly surface wind anomaly over the western Pacific is hypothesized to prolong the La Niña condition. Slow oceanic adjustment processes are likely to build up the equatorial heat content and eventually terminate the La Niña event (e.g., Jin 1997; Meinen and McPhaden 2000).

The purpose of this study is to test the hypothesis formulated in Okumura and Deser (2010) by expanding upon the AGCM experiments presented in Ohba and Ueda (2009). We conduct additional experiments to address the following questions: 1 ) What are the relative contributions of SST anomalies inside and outside the equatorial Pacific to surface wind anomalies over the western Pacific associated with El Niño and La Niña? and 2) Does the zonal displacement of Pacific precipitation anomalies change the balance of wind forcing over the western Pacific between El Niño and La Niña? The paper is organized as follows. The AGCM experiments are described in section 2. Section 3 describes the results, and section 4 provides a summary.

\section{Model experiments}

The numerical experiments are conducted with the AGCM developed at the Meteorological Research Institute (MRI) in Japan (Shibata et al. 1999; Yukimoto et al. 2001, 2006). We use a version with T42 horizontal resolution $\left(\sim 2.8^{\circ}\right.$ latitude $\times 2.8^{\circ}$ longitude $)$ and 30 hybrid sigma-pressure levels in the vertical. In the control simulation, the model is forced with monthly climatological SSTs based on Levitus and Boyer (1994) and integrated for $30 \mathrm{yr}$. As in Ohba and Ueda (2009), two sets of 15-member ensemble simulations are conducted by adding monthly SST anomalies for El Niño and La Niña over the Indian Ocean and Pacific $\left(40^{\circ} \mathrm{S}-40^{\circ} \mathrm{N}\right.$, $30^{\circ} \mathrm{E}-60^{\circ} \mathrm{W}$ ) from January of the developing year through November of the following year ("IO + PAC" runs). The SST forcing for the El Niño and La Niña
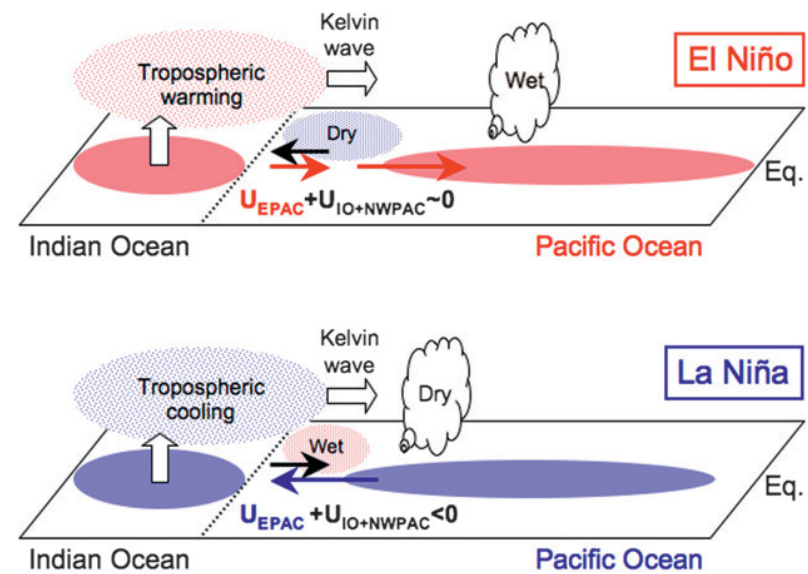

FIG. 2. Schematic diagram illustrating the hypothesized cause of the asymmetric wind response in the far western equatorial Pacific between (top) El Niño and (bottom) La Niña during the mature phase. Pink (blue)-shaded ellipses depict positive (negative) SST anomalies over the Pacific and Indian Oceans. Red (blue) arrows indicate surface wind anomalies forced by equatorial Pacific SST anomalies during El Niño (La Niña); black arrows indicate surface wind anomalies forced by Indian Ocean and northwest tropical Pacific SST anomalies. During El Niño (La Niña), the atmospheric Kelvin wave forced by tropospheric warming (cooling) over the Indian Ocean induces an easterly (westerly) surface wind anomaly in the far western equatorial Pacific. In the MRI AGCM, the northwest tropical Pacific cooling (warming) and associated precipitation decrease (increase) also force an easterly (westerly) surface wind anomaly to their south. These easterly (westerly) surface wind anomalies forced by the Indian Ocean and northwest tropical Pacific SST anomalies balance (fail to balance) the westerly (easterly) surface wind anomaly forced by equatorial Pacific precipitation anomalies over the far western equatorial Pacific during El Niño (La Niña). The lack of balance of the surface wind anomalies over the far western Pacific during La Niña results from the westward shift of the Pacific precipitation anomaly because of the nonlinear dependence of atmospheric deep convection on the absolute SST. The net easterly surface wind anomaly over the far western Pacific during La Niña is hypothesized to prolong the event. Modified after Okumura and Deser (2010).

experiments is identical except for the sign of the anomalies and is derived from a composite El Niño minus La Niña using the extended reconstructed SST version 2 (Smith and Reynolds 2004). The five strongest El Niño (1965, 1972, 1982, 1987, and 1997) and La Niña (1955, 1973, 1988, 1998, and 1999) years based on the December-February (DJF) SST anomalies averaged in the Niño-3.4 region $\left(5^{\circ} \mathrm{S}-5^{\circ} \mathrm{N}, 170^{\circ}-120^{\circ} \mathrm{W}\right)$ are used for the composite (see the second row of Fig. 3 for the SST anomaly pattern in DJF). The 15 different initial conditions for the ensemble runs are taken from 1 January states of the control simulation.

In addition to the $\mathrm{IO}+\mathrm{PAC}$ runs, two more sets of 15-member ensemble simulations are conducted by limiting the SST forcing to the equatorial Pacific. In 
Observation \& MRI AGCM: SST, Precipitation \& Surface Wind (DJF) El Nino
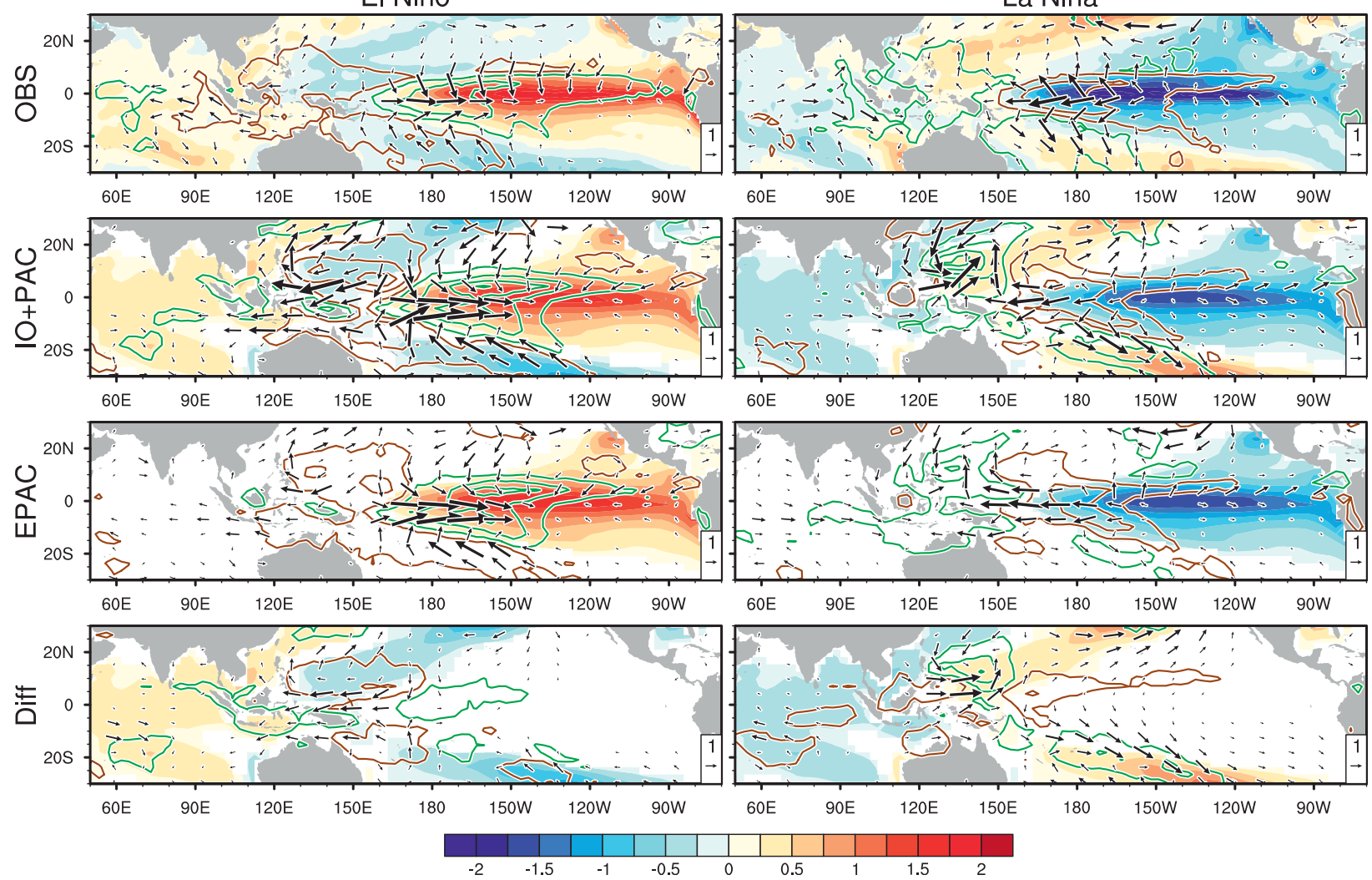

FIG. 3. DJF anomalies of SST $\left({ }^{\circ} \mathrm{C}\right.$, color shading), surface wind $\left(\mathrm{m} \mathrm{s}^{-1}\right.$, vectors), and precipitation [mm day ${ }^{-1}$; positive (negative) contours in green (orange) at $\pm 1,4,7, \ldots$ ] for (left) El Niño and (right) La Niña from (top row) observations and (bottom three rows) MRI AGCM experiments (IO + PAC, EPAC, and their difference). The observational composite maps are based on the same methods and datasets as in Fig. 1.

these "EPAC" runs, we prescribe only the positive and negative SST anomalies east of $160^{\circ} \mathrm{E}$ for El Niño and La Niña, respectively. Note that these SST anomalies extend into the subtropical Pacific off the west coast of the Americas (Fig. 3, third row). By comparing the $\mathrm{IO}+\mathrm{PAC}$ and EPAC runs, we can assess how SST anomalies outside the equatorial Pacific modify the surface wind response to the equatorial Pacific SSTs. Additional experiments suggest that the impacts of SST anomalies inside and outside the equatorial Pacific are nearly linear (not shown), in agreement with Annamalai et al. (2005). The pattern, amplitude, and seasonal evolution of SST forcing are perfectly symmetrical between El Niño and La Niña in both the IO + PAC and EPAC runs, and therefore any asymmetry in the AGCM's response can be attributed to nonlinear atmospheric processes. In the next section, we will present ensemble-mean anomalies in the IO + PAC and EPAC runs relative to the climatology of the control simulation.

\section{Results}

In this section we focus on the atmospheric response in boreal winter (DJF) when the asymmetry between El Niño and La Niña becomes evident in surface wind anomalies over the far western Pacific (Fig. 1). Figure 3 shows SST, surface wind, and precipitation anomalies in the AGCM experiments, as well as composite maps based on observations. In the IO + PAC runs, the MRI AGCM successfully simulates the observed patterns of precipitation and surface wind anomalies for El Niño and La Niña, although the model's response is too strong in the Pacific, particularly over the warm pool region, and too weak in the eastern Indian Ocean. Despite the symmetric SST forcing in the model experiments, the center of the Pacific precipitation anomalies is displaced westward for La Niña compared to El Niño, consistent with the observations and earlier model studies (Hoerling et al. 1997; Kang and Kug 2002; Ohba and Ueda 2009). The longitudinal shift of the precipitation 


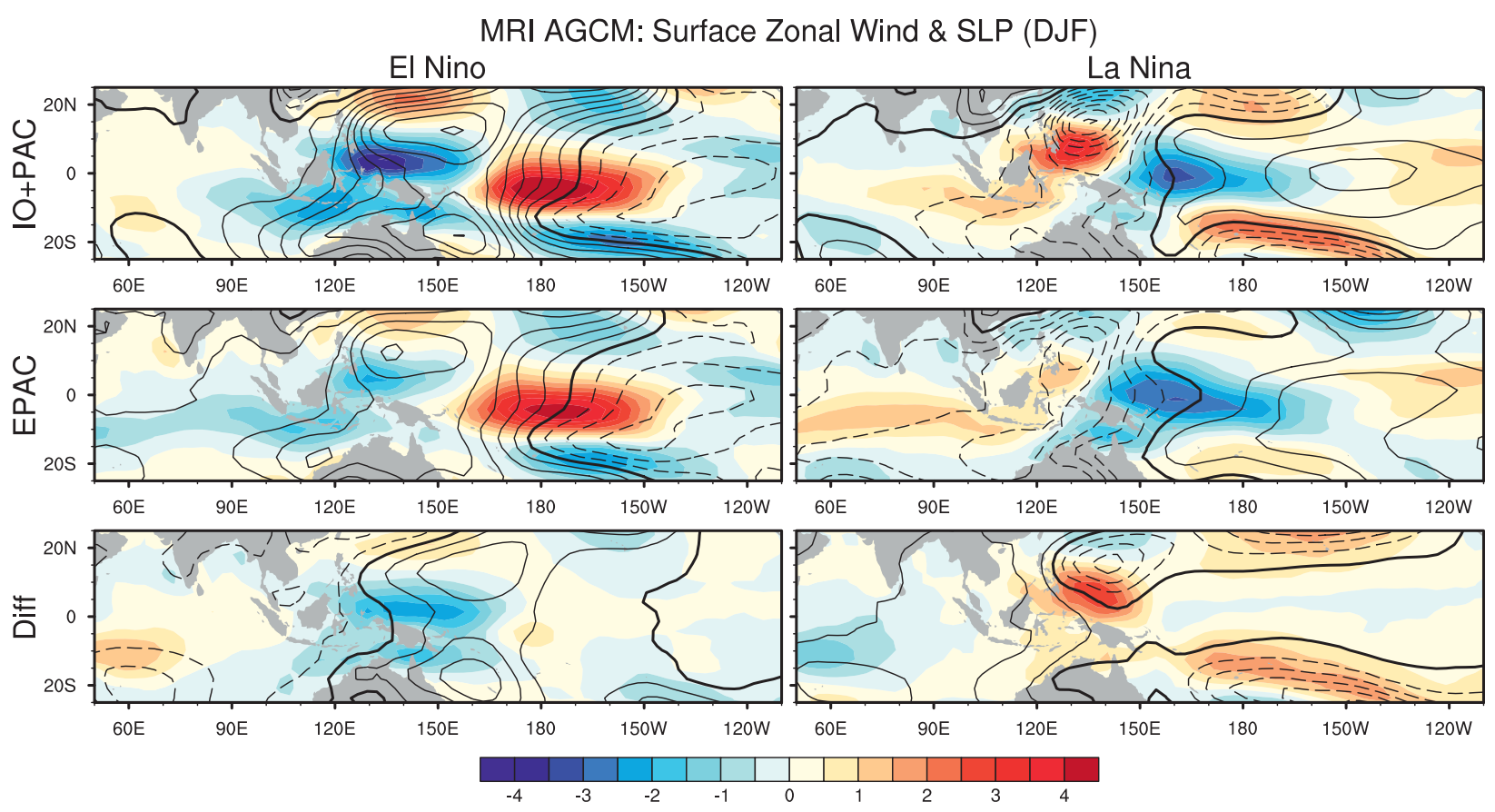

FIG. 4. DJF anomalies of surface zonal wind ( $\mathrm{m} \mathrm{s}^{-1}$, color shading) and SLP (hPa, contours at intervals of 0.4$)$ for (left) El Niño and (right) La Niña in the MRI AGCM experiments: (top) IO + PAC and (middle) EPAC runs and (bottom) their difference.

anomalies is more pronounced in the model $\left(20^{\circ}-30^{\circ}\right)$ than in the observations $\left(10^{\circ}-15^{\circ}\right)$ because of the more eastward location of the positive precipitation anomalies during El Niño in the model compared to the observations. In the northwest tropical Pacific, opposite-signed precipitation anomalies and associated atmospheric circulation anomalies also show an asymmetry in their zonal extent between the El Niño and La Niña experiments, consistent with a recent study by Wu et al. (2010). In association with the zonal shift of the precipitation anomaly patterns, anomalous easterly winds extend into the far western Pacific in the La Niña experiment, while anomalous westerly winds are limited to the east of $160^{\circ} \mathrm{E}$ (with anomalous easterly winds over the far western Pacific) in the El Niño experiment.

The zonal displacement of precipitation and surface wind anomalies in the Pacific is reproduced in the EPAC runs, confirming that the model atmosphere responds nonlinearly to equatorial Pacific SSTs (Fig. 3, third row). The opposite-signed precipitation anomalies appear over the northwest tropical Pacific in the absence of local SST anomalies due to adjustments in the Walker circulation. Compared to the IO + PAC runs, precipitation anomalies are reduced not only in the northwest tropical Pacific but also slightly in the equatorial Pacific.

The impact of Indian Ocean and off-equatorial Pacific SST anomalies is inferred from the difference between the IO + PAC and EPAC runs (Fig. 3, bottom row). During El Niño, the Indian Ocean warming and northwest/southwest tropical Pacific cooling induce anomalous easterly winds in the western Pacific, weakening the anomalous westerly winds forced by the equatorial Pacific warming. These easterly wind anomalies are enhanced north of the equator by the anticyclonic circulation anomaly that develops over the negative SST anomalies east of the Philippine Islands. During La Niña, the surface wind response to SST anomalies outside the equatorial Pacific is similar to those associated with El Niño with the sign reversed, although the anomalous westerly winds over the far western Pacific are stronger and extend less to the east compared to the anomalous easterly winds during El Niño. Thus, SST anomalies outside the equatorial Pacific produce a negative feedback during both El Niño and La Niña.

Figure 4 shows surface zonal wind and sea level pressure (SLP) anomalies in the IO + PAC and EPAC runs and their difference for El Niño and La Niña. In both the IO + PAC and EPAC runs, SLP anomalies exhibit a zonal seesaw pattern over the tropical Pacific. The SLP anomalies have a local extremum on (off) the equator in the eastern (western) Pacific, indicative of equatorial Kelvin (Rossby) wave forced by changes in precipitation and associated diabatic heating. Within a few degrees of the equator-the equatorial radius of deformation for the ocean-anomalous zonal winds are 

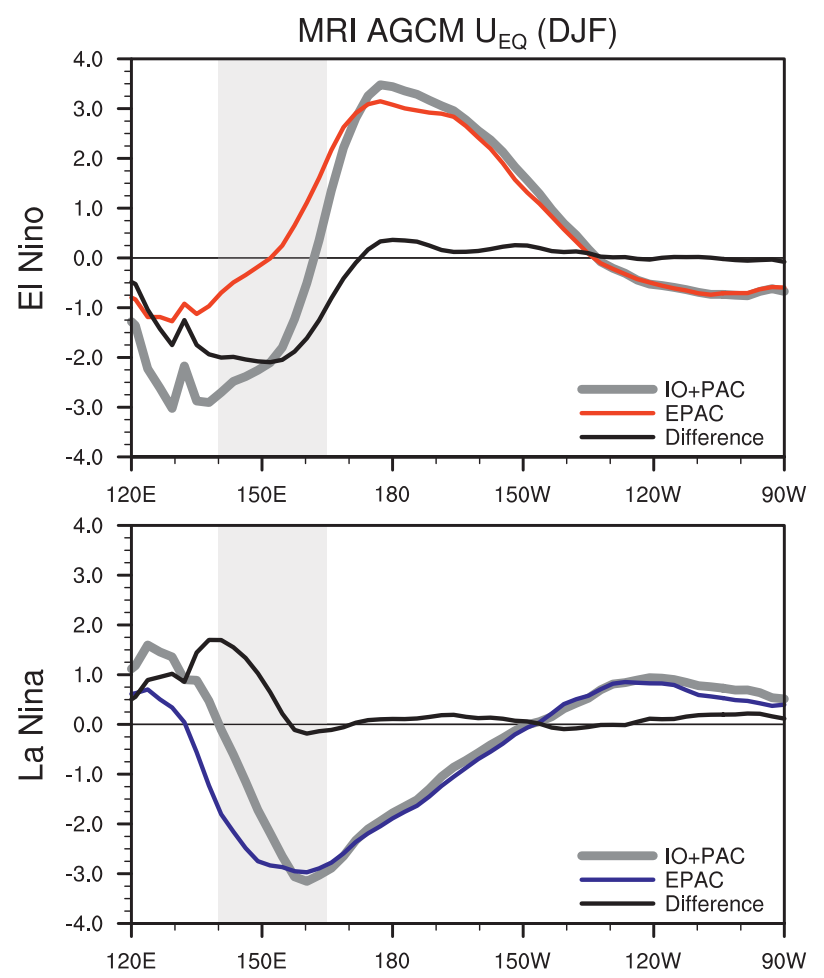

FIG. 5. DJF surface zonal wind anomalies along the equator $\left(3^{\circ} \mathrm{S}-3^{\circ} \mathrm{N}\right)$ for (top) El Niño and (bottom) La Niña in the MRI AGCM experiments: IO + PAC (thick gray), EPAC (red in the El Niño panel; blue in the La Niña panel), and their difference (black). The gray shading indicates the far western equatorial $\mathrm{Pa}$ cific $\left(140^{\circ}-165^{\circ} \mathrm{E}\right)$, where the wind response exhibits strong asymmetry between the El Niño and La Niña experiments.

directed down the anomalous zonal pressure gradient. The largest equatorial zonal wind change is found near the node of the Pacific SLP seesaw, with the center displaced westward by $20^{\circ}-30^{\circ}$ during La Niña compared to El Niño.

In the IO + PAC El Niño experiment, the sign of the equatorial zonal wind and SLP gradient anomalies is reversed west of $160^{\circ} \mathrm{E}$ and anomalous easterly winds of up to $3 \mathrm{~m} \mathrm{~s}^{-1}$ extend into the far western Pacific (Fig. 4). In the EPAC El Niño experiment, a similar feature is present to the west of $130^{\circ} \mathrm{E}$, but the SLP gradient and zonal wind anomalies are nearly absent between $140^{\circ}$ and $160^{\circ} \mathrm{E}$. The difference map shows that the enhanced eastward SLP gradient over the far western Pacific in the $\mathrm{IO}+\mathrm{PAC}$ experiment compared to the EPAC experiment is due to anomalous low pressure extending eastward along the equator from the Indian Ocean and anomalous high pressure extending westward from the northwest/southwest tropical Pacific. Thus, it is suggested that both the atmospheric Kelvin wave forced by the Indian Ocean warming and Rossby wave forced by the off-equatorial Pacific cooling induce anomalous easterly winds over the far western Pacific in the $\mathrm{IO}+$ PAC El Niño experiment. Because of the presence of New Guinea Island, equatorial winds in the far western Pacific appear to be more strongly affected by SST anomalies over the northwest than southwest tropical Pacific. The SLP difference map for the La Niña experiments shows a very similar pattern with reversed sign, suggesting that the same mechanism is at work. The impact of SST anomalies outside the equatorial Pacific, however, is not strong enough to affect the net surface wind anomaly in the IO + PAC La Niña experiment.

Additional experiments forced with SST anomalies over the full Pacific suggest that the relative contribution of Indian Ocean and off-equatorial Pacific SST anomalies to surface wind anomalies over the far western Pacific is seasonally dependent (not shown). The Indian Ocean SSTs begin to play a dominant role a few months after the mature phase of El Niño and La Niña when the Indian Ocean SST anomalies reach their delayed peak and the off-equatorial Pacific SST anomalies start to decay. Before and during the mature phase, the Indian Ocean and off-equatorial Pacific SSTs make comparable contributions. Note that the excessive (insufficient) precipitation and wind anomalies over the Pacific warm pool region (the Indian Ocean) in the MRI AGCM (Fig. 3) may suggest that this model overestimates (underestimates) the impact of off-equatorial Pacific (Indian Ocean) SST anomalies. In the IO + PAC El Niño experiment, anomalous westerly winds start to decay over the far western Pacific in boreal summer when negative SST anomalies develop in the western Pacific (not shown), nearly two seasons earlier than in the observations (Fig. 1). Annamalai et al. (2010) suggest that SST anomalies in the Indonesian seas also affect the seasonal evolution of El Niño. Further model intercomparison studies are necessary to address the relative importance of these regional SST anomalies.

Figure 5 summarizes the contributions to surface zonal wind anomalies along the equator in the El Niño and La Niña experiments. The wind anomalies forced by the equatorial Pacific (Indian Ocean and off-equatorial Pacific) SST anomalies in the EPAC (IO + PAC minus EPAC) runs are shown in colored (black) lines following the color scheme in the schematic plot of Fig. 2. The light gray shading indicates the far western Pacific $\left(140^{\circ}-\right.$ $165^{\circ} \mathrm{E}$ ), where the total wind anomalies in the IO + PAC run (thick gray curves) exhibit strong asymmetry between El Niño and La Niña. In the far western Pacific, the zonal winds forced by the Indian Ocean and offequatorial Pacific SST anomalies are of opposite sign and similar magnitude for El Niño and La Niña. Because of the nonlinear atmospheric response, the zonal winds forced by the equatorial Pacific SST anomalies are 
smaller (larger) in magnitude than the zonal winds forced by the SST anomalies outside the equatorial Pacific in the El Niño (La Niña) experiment. As a result, the net surface winds in the far western Pacific are easterly with magnitudes up to $3 \mathrm{~m} \mathrm{~s}^{-1}$ in both the El Niño and La Niña experiments. When the MRI AGCM is coupled to an ocean model, these anomalous easterly winds force an upwelling oceanic Kelvin wave and rapidly terminate the El Niño event (Ohba and Ueda 2007). A similar experiment needs to be conducted for La Niña to examine the influence of persistent easterly wind anomalies on the ocean. Our AGCM experiments suggest that the impact of SST anomalies outside (within) the equatorial Pacific dominates the surface zonal wind response over the far western Pacific in the El Niño (La Niña) experiment. The zonal displacement of precipitation and surface wind anomalies in the Pacific causes this difference in the balance of surface wind forcing between the IO + PAC El Niño and La Niña experiments.

\section{Summary}

Recent studies show that La Niña tends to persist longer than El Niño. The MRI AGCM experiments support the hypothesis proposed by Okumura and Deser (2010) that the nonlinear atmospheric response to equatorial Pacific SSTs is a fundamental cause of the asymmetry in the duration of El Niño and La Niña. During the mature phase of El Niño and La Niña, SST anomalies outside the equatorial Pacific induce surface wind anomalies over the far western Pacific that act to weaken the equatorial Pacific SST anomalies. In addition to the Indian Ocean that was discussed in Okumura and Deser (2010), SST anomalies in the northwest tropical Pacific also play an important role for the wind response over the far western Pacific in the MRI AGCM (Fig. 2). These wind anomalies forced by SST anomalies outside the equatorial Pacific have a similar amplitude between El Niño and La Niña but affect the sign of net surface wind anomalies only during El Niño. During La Niña, the influence of equatorial Pacific SST anomalies dominates the surface wind response over the far western Pacific because of the westward displacement of the precipitation anomalies. Further modeling studies are necessary to examine the oceanic response to the asymmetric wind anomalies and the role of oceanatmosphere interactions in the subsequent seasonal evolution of warm and cold events.

The results presented in this study may have important implications for climate prediction. The differing duration of El Niño and La Niña is likely to affect the persistence of their global atmospheric teleconnections, which in turn induce climate anomalies not only in the Indo-Pacific region but also at mid- and high latitudes. For example, the long-lasting La Niña of 1998-2001 caused extensive drought across the United States, southern Europe, and southwest Asia (e.g., Hoerling and Kumar 2003). In the central North Pacific, ocean temperature anomalies associated with atmospheric teleconnections show distinct asymmetry in duration between El Niño and La Niña (Deser et al. 2011, manuscript submitted to J. Climate). The asymmetric termination process of El Niño and La Niña may also affect the mechanisms of onset of ensuing events. Finally, the strong asymmetry of El Niño and La Niña calls for caution in the application of linear analysis methods for the study of ENSO.

Acknowledgments. We acknowledge Drs. A. Kitoh, T. Ose, S. Yukimoto, and O. Arakawa for providing the model code. We thank the anonymous reviewers for their useful suggestions.

\section{REFERENCES}

Annamalai, H., S.-P. Xie, J. P. McCreary, and R. Murtugudde, 2005: Impact of Indian Ocean sea surface temperature on developing El Niño. J. Climate, 18, 302-319.

_ S. Kida, and J. Hafner, 2010: Potential impact of the tropical Indian Ocean-Indonesian seas on El Niño characteristics. J. Climate, 23, 3933-3952.

Burgers, G., and D. B. Stephenson, 1999: The "normality" of El Niño. Geophys. Res. Lett., 26, 1027-1030.

Hoerling, M., and A. Kumar, 2003: The perfect ocean for drought. Science, 299, 691-694.

— — - _ and M. Zhong, 1997: El Niño, La Niña, and the nonlinearity of their teleconnections. J. Climate, 10, 1769-1786.

Jin, F.-F., 1997: An equatorial ocean recharge paradigm for ENSO. Part I: Conceptual model. J. Atmos. Sci., 54, 811-829.

—, S.-I. An, A. Timmermann, and J. Zhao, 2003: Strong El Niño events and nonlinear dynamical heating. Geophys. Res. Lett., 30, 1120, doi:10.1029/2002GL016356.

Kanamitsu, M., W. Ebisuzaki, J. Woollen, S.-K. Yang, J. J. Hnilo, M. Fiorino, and G. L. Potter, 2002: NCEP-DOE AMIP-II Reanalysis (R-2). Bull. Amer. Meteor. Soc., 83, 1631-1643.

Kang, I.-S., and J.-S. Kug, 2002: El Niño and La Niña sea surface temperature anomalies: Asymmetry characteristics associated with their wind stress anomalies. J. Geophys. Res., 107, 4372, doi:10.1029/2001JD000393.

Kessler, W. S., 2002: Is ENSO a cycle or a series of events? Geophys. Res. Lett., 29, 2125, doi:10.1029/2002GL015924.

Kug, J.-S., and I.-S. Kang, 2006: Interactive feedback between ENSO and the Indian Ocean. J. Climate, 19, 1784-1801.

Larkin, N. K., and D. E. Harrison, 2002: ENSO warm (El Niño) and cold (La Niña) event life cycles: Ocean surface anomaly patterns, their symmetries, asymmetries, and implications. J. Climate, 15, 1118-1140.

Lau, N.-C., and M. J. Nath, 2003: Atmosphere-ocean variations in the Indo-Pacific sector during ENSO episodes. J. Climate, 16, 3-20. 
Levitus, S., and T. P. Boyer, 1994: Temperature. Vol. 4, World Ocean Atlas 1994, NOAA Atlas NESDIS 4, 117 pp.

McPhaden, M. J., and X. Zhang, 2009: Asymmetry in zonal phase propagation of ENSO sea surface temperature anomalies Geophys. Res. Lett., 36, L13703, doi:10.1029/2009GL038774.

Meinen, C. S., and M. J. McPhaden, 2000: Observations of warm water volume changes in the equatorial Pacific and their relationship to El Niño and La Niña. J. Climate, 13, 3551-3559.

Ohba, M., and H. Ueda, 2007: An impact of SST anomalies in the Indian Ocean in acceleration of the El Niño to La Niña transition. J. Meteor. Soc. Japan, 85, 335-348.

_ and _- 2009: Role of nonlinear atmospheric response to SST on the asymmetric transition process of ENSO.J. Climate, 22, 177-192.

- D. Nohara, and H. Ueda, 2010: Simulation of asymmetric ENSO transition in WCRP CMIP3 multimodel experiments. J. Climate, 23, 6051-6067.

Okumura, Y. M., and C. Deser, 2010: Asymmetry in the duration of El Niño and La Niña. J. Climate, 23, 5826-5843.

Reynolds, R. W., N. A. Rayner, T. M. Smith, D. C. Stokes, and W. Q. Wang, 2002: An improved in situ and satellite SST analysis for climate. J. Climate, 15, 1609-1625.

Shibata, K., H. Yoshimura, M. Ohizumi, M. Hosaka, and M. Sugi, 1999: A simulation of troposphere, stratosphere and mesosphere with an MRI/JMA98 GCM. Pap. Meteor. Geophys., 50, 15-53.
Smith, T. M., and R. W. Reynolds, 2004: Improved extended reconstruction of SST (1854-1997). J. Climate, 17, 2466-2477.

Wang, B., R. Wu, and X. Fu, 2000: Pacific-East Asia teleconnection: How does ENSO affect East Asian climate? J. Climate, 13, 1517-1536.

Watanabe, M., and F.-F. Jin, 2002: Role of Indian Ocean warming in the development of Philippine Sea anticyclone during ENSO. Geophys. Res. Lett., 29, 1478, doi:10.1029/ 2001 GL014318.

Wu, B., T. Li, and T. Zhou, 2010: Asymmetry of atmospheric circulation anomalies over the western North Pacific between El Niño and La Niña. J. Climate, 23, 4807-4822.

Xie, P., and P. A. Arkin, 1996: Analyses of global monthly precipitation using gauge observations, satellite estimates, and numerical model predictions. J. Climate, 9, 840-858.

Xie, S.-P., K. Hu, J. Hafner, H. Tokinaga, Y. Du, G. Huang, and T. Sampe, 2009: Indian Ocean capacitor effect on Indowestern Pacific climate during the summer following El Niño. J. Climate, 22, 730-747.

Yukimoto, S., and Coauthors, 2001: The new Meteorological Research Institute Coupled GCM (MRI-CGCM2)-Model climate and variability. Pap. Meteor. Geophys., 51, 47-88.

- and Coauthors, 2006: Present-day climate and climate sensitivity in the Meteorological Research Institute Coupled GCM version 2.3 (MRI-CGCM2.3). J. Meteor. Soc. Japan, 84, 333-363. 